\title{
Numerical Simulation and Computational Flow Characterization Analyses of Centrifugal Pump Operating as Turbine
}

\author{
Du Jianguo,, ${ }^{1}$ Guanghui Chang, ${ }^{1}$ Daniel Adu ${ }^{10},{ }^{1,2}$ Ransford Darko, ${ }^{3}$ \\ Muhammad A. S. Khan, ${ }^{1}$ and Eric O. Antwi ${ }^{4}$ \\ ${ }^{1}$ School of Management Science \& Eng., Jiangsu University, Zhenjiang 212013, China \\ ${ }^{2}$ Faculty of Engineering, Accra Technical University, Barnes Road, Accra, Ghana \\ ${ }^{3}$ Department of Agricultural Engineering, University of Cape Coast PMB 233, Cape Coast, Ghana \\ ${ }^{4}$ Department of Energy and Environmental Engineering, University of Energy and Natural Resources Sunyani, Sunyani, Ghana
}

Correspondence should be addressed to Daniel Adu; adudaniel39@yahoo.com

Received 29 April 2021; Revised 14 July 2021; Accepted 13 August 2021; Published 21 August 2021

Academic Editor: Xiaoqing Bai

Copyright ( $\odot 2021 \mathrm{Du}$ Jianguo et al. This is an open access article distributed under the Creative Commons Attribution License, which permits unrestricted use, distribution, and reproduction in any medium, provided the original work is properly cited.

Using a pump in reverse mode as a hydraulic turbine remains an alternative for hydropower generation in meeting energy needs, especially for the provision of electricity to remote and rural settlements. The primary challenge with small hydroelectric systems is attributed to the high price of smaller size hydraulic turbines. A specific commercial pump model, with a flow rate of $12.5 \mathrm{~m}^{3} / \mathrm{h}$, head $32 \mathrm{~m}$, pressure side diameter of $50 \mathrm{~mm}$, impeller out, and inlet diameters of $160 \mathrm{~mm}$ and $6 \mathrm{~mm}$, respectively, was chosen for this research. This research aimed to investigate a pump's flow characteristics as a turbine to help select a suitable pump to be used as a turbine for micro- or small hydropower construction. Numerical methodologies have been adopted to contribute to the thoughtful knowledge of pressure and velocity distribution in the pump turbine performance. In this study, the unsteady flow relations amongst the rotating impeller and stationary volute of the centrifugal pump made up four blades and four splitters. Intermittent simulation results of pressure and velocity flow characteristics were studied considering diverse impeller suction angles. The study was conducted by considering a wide range of rotational speeds starting from $750 \mathrm{rpm}$ to $3250 \mathrm{rpm}$. From the results, it was found that PAT operation was improved when operated at low speeds compared to high-speed operation. Thus, speeds between $1500 \mathrm{rpm}$ and $2000 \mathrm{rpm}$ were suitable for PAT performance. This research helps to realize the unsteady flow physiognomies, which provide information for future research on PAT. This study makes useful facts available which could be helpful for the pump turbine development. Future studies should focus on cost analysis and emission generation in energy generation.

\section{Introduction}

Centrifugal pumps are commonly used for domestic and industrial applications such as water supply, energy generation, flood control, irrigation for agricultural purposes, and transportation of liquid-solid mixtures. Designs of hydropower plants are based on its ability to function at allout efficiency matching with acceptable speed. Hydroturbine performance rests on its speed; therefore, it is manufactured to function at the greatest attainable efficiency in a specific rapidity. The role head is to provide speed since the speed rests on its head. The ability of the head variation can affect the performance of the turbine. Therefore, it is essential for the adjustment of rotational speed to result in a possible allout efficiency $[1,2]$. PAT A can, in general, take care of higher flow rates, which sequentially could implicate higher output energy ranges [3]. Nevertheless, since pump producers have not made available pump performance curves in turbine mode, it is usually not easy to select an appropriate pump turbine to run suitably at specific operating conditions, which has become a significant challenge [4]. Several investigational and theoretical research studies were carried out on the performance of pumps running in reverse [5]. The easiest way is the pump model-based prediction since the 
user only needs to have access to the necessary information of the pump performance studies, for example, QP, HP, and $\eta \mathrm{P}$, as it makes finding correspondent in turbine mode operation easier using simple scheming. As a result, much attention was given to pump mode performance parameters by theoretical researchers such as [6-8]. Many researchers like [9-11] have established some PAT relationships with precise pump speed. Various researchers have continually conducted several research pieces to provide a PAT general performance prediction method [12-14]. Comparative research was conducted by Hossain et al. [15], not forgetting $[8,16]$ methods to come out with a knowledge edge that is better than the others. The method of [16-18] was discovered to offer a deeper understanding of PAT performance characteristics; they consist of the "area ratio," which was a theoretical method developed in [19-21]. A study was conducted to investigate material consumption and carbon emissions in selected towns and provinces in China. The outcome was that total infrastructure building delivery in the selected towns was not leveled. Thus, infrastructure building supply remained steady along with economic growth [22]. Cao et al. carried out an experiment and numerical study on snowdrift on a typical large-span retractable roof utilizing the Euler-Euler technique. It was revealed that not one unchanging snow delivery on the roofs was different, which must be well thoughtout [23]. Other researchers also researched the various turbines for power generation, axial flow pumps, and energy conservation. [24-26]. A standardized pump can operate as a hydraulic turbine deprived of modifications to the casing or the impeller geometry. Consideration should only be given to the selection of appropriate flow rate $(Q)$, head $(H)$, and speed $(n)$ for a site. It is conceivable to attain an equally high PAT efficiency level as that of pump mode operation in most cases. At best turbine mode operation, the impact of PAT on pressure movement is controlled. The dissimilarity of shared shock loss controls a major part of the energy from the fluid which is then transported open-air through the shaft by PAT. The power take out could be utilized again, either in a mechanical or electrical form. The dissimilarity between the turbine and the pump rests on their rotational bearing, which is indicated by an arrow, as shown in Figure 1. Additionally, the turbine head usually has a higher head and flow at BEP (best efficiency point) than the pump mode at equal speed. Table 1 shows the comparison of methods to obtain BEP for PAT proposed by previous researchers.

\section{Centrifugal Pump Model}

A specific commercial pump model, which has four main blades and four splitter, head at $16 \mathrm{~m}$, flow rate of $12.5 \mathrm{~m}^{3} / \mathrm{h}$, and running at a speed of $2900 \mathrm{rpm}$, was carefully chosen for the paper. The pump is mainly composed of long straight pipes, as shown in [27]. The entire computational flow domains were generated using three-dimensional (3D) Pro/ $E 5.0$ software. The long straight pipes at the impeller inlet and volute outlet were adequately extended to make the simulation more accurate. Figure 2 displays the complete model of the selected commercial pump.
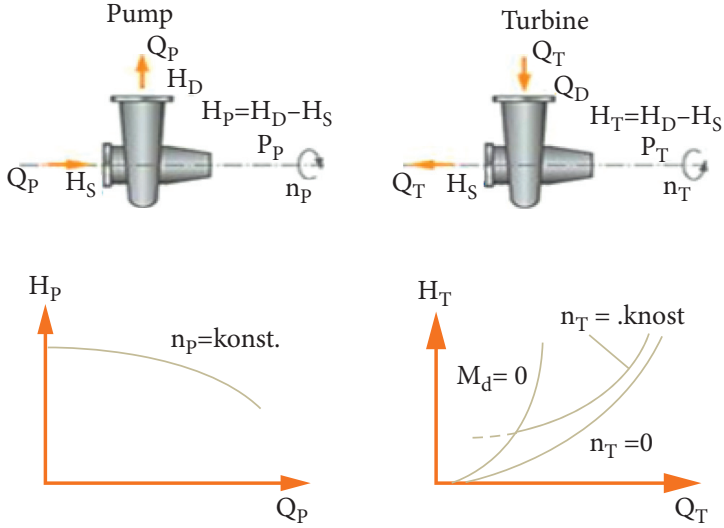

FIgURE 1: Structure of dissimilarity amongst pump and turbine modes.

Summary of the scheme parameters and hydraulic evaluation description of the selected centrifugal pump model under the study are presented in Table 2.

\section{Numerical Simulations}

3.1. Computational Domains. Meshing is the process of discretizing a region under consideration to a set of the control volume. Mesh for diverse PAT scheme parts such as volute covering, wearing the ring, and front plus back chambers is generated in ANSYS ICEM 14.5. The CFD calculation method was used. An unstructured grid with a tetrahedral mesh was selected to represent and create all the parts of PAT fluid domains. Since mesh of this type has outstanding compliance, particularly for flows which has complicated border situations. Mesh independence study was performed by Zhang et al. [28], and the results show that mesh size of 1.65 was selected for creating the computational domain, bearing in mind the structure of the applied computing, for which Figure 3 provides the pictures of the whole mesh areas.

3.2. Transient Simulation Setup. In carrying out a numerical study, ANSYS CFX code 16 was chosen for creating PAT geometry. The K-omega $(\mathrm{k}-\omega)$ turbulence model was selected for the study [8]:

$$
\frac{\partial \mathbf{k}}{\partial \mathbf{t}}+\mathbf{U}_{\mathrm{j}} \frac{\partial \mathbf{k}}{\partial \mathbf{x}_{\mathbf{j}}}=\mathbf{P}_{\mathbf{k}}-\boldsymbol{\beta}^{*} \mathbf{k} \boldsymbol{\omega}+\frac{\partial}{\partial \mathbf{x}_{\mathbf{j}}}\left(\mathbf{v}+\boldsymbol{\sigma}_{\mathbf{k}} \mathbf{v}_{\mathrm{T}}\right) \frac{\partial \mathbf{k}}{\partial \mathbf{x}_{\mathbf{j}}},
$$

Specific dissipation rate:

$$
\begin{aligned}
\frac{\partial \boldsymbol{\omega}}{\partial \mathbf{t}}+\mathbf{U}_{\mathrm{j}} \frac{\partial \boldsymbol{\omega}}{\partial \mathbf{x}_{\mathbf{j}}}= & \propto \mathbf{s}^{2}-\boldsymbol{\beta} \boldsymbol{\omega}^{2}+\frac{\partial}{\partial \mathbf{x}_{\mathbf{j}}}\left(\mathbf{v}+\boldsymbol{\sigma}_{\boldsymbol{\omega}} \mathbf{v}_{\mathrm{T}}\right) \frac{\partial \boldsymbol{\omega}}{\partial \mathbf{x}_{\mathbf{j}}} \\
& +2\left(1-\mathbf{F}_{1}\right) \boldsymbol{\sigma}_{\boldsymbol{\omega} \boldsymbol{2}} \frac{1}{\boldsymbol{\omega}} \frac{\partial \mathbf{k}}{\partial \mathbf{x}} \frac{\partial \boldsymbol{\omega}}{\partial \mathbf{x}_{\mathbf{i}}} .
\end{aligned}
$$

The values $\mathbf{k}$ and $\boldsymbol{\omega}$ follow closely after the transport equations for turbulent kinetic energy as well as the dissipation range of turbulence [6]. 
TABle 1: Comparison methods to obtain BEP for PAT.

\begin{tabular}{|c|c|c|c|c|c|c|c|c|c|c|c|c|}
\hline$N_{\mathrm{s}}\left(\mathrm{m}, \mathrm{m}^{3} / \mathrm{s}\right)$ & $\eta_{\text {Pmax }}(\%)$ & $D(\mathrm{~m})$ & $\mathrm{h}$ & $\mathrm{q}$ & $\mathrm{h}$ & $\mathrm{q}$ & $\mathrm{h}$ & $\mathrm{q}$ & $\mathrm{h}$ & $\mathrm{q}$ & $\mathrm{h}$ & $\mathrm{q}$ \\
\hline 14.6 & 65.5 & 0.250 & 2.05 & 1.56 & 1.63 & 1.28 & 1.78 & 1.45 & 2.20 & 2.09 & 2.14 & 1.48 \\
\hline 14.7 (Williams, 1992) & 46 & 0.125 & 2.87 & 1.63 & 2.17 & 1.47 & 2.54 & 1.86 & 2.84 & 2.4 & 2.71 & 1.72 \\
\hline 20.7 (micro-hydropower development, 2003) & 60 & 0.160 & 2.24 & 1.73 & 1.84 & 1.42 & 2.4 & 1.66 & 2.22 & 2.04 & 2.29 & 1.74 \\
\hline 23.0 & 76 & 0.250 & 1.95 & 1.59 & 1.41 & 1.19 & 1.49 & 1.29 & 1.78 & 1.76 & 1.94 & 1.60 \\
\hline 34.8 (Joshi S., 2005) & 83 & - & 1.71 & 1.55 & 1.28 & 1.14 & 1.34 & 1.20 & 1.49 & 1.36 & 1.70 & 1.48 \\
\hline 36.4 (Singh, 2005) & 74.4 & 0.175 & 1.72 & 1.54 & 1.81 & 1.34 & 1.43 & 1.27 & 1.73 & 1.78 & 1.71 & 1.50 \\
\hline 37.7 & 86.5 & 0.250 & 1.73 & 1.48 & 1.24 & 1.11 & 1.27 & 1.16 & 1.34 & 1.16 & 1.65 & 1.44 \\
\hline 45.2 (Singh, 2005) & 80 & 0.200 & 1.40 & 1.38 & 1.56 & 1.25 & 1.31 & 1.2 & 1.51 & 1.49 & 1.51 & 1.33 \\
\hline 55.6 & 87 & 0.250 & 1.34 & 1.15 & 1.23 & 1.11 & 1.26 & 1.16 & 1.32 & 1.13 & 1.38 & 1.18 \\
\hline
\end{tabular}

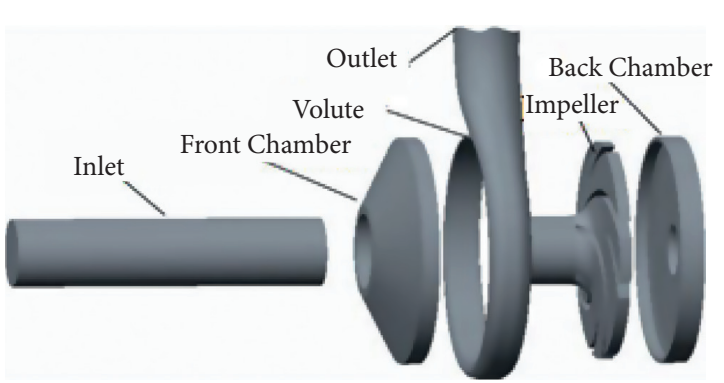

Figure 2: Complete 3D model of the selected centrifugal pump.

TABLE 2: Scheme parameters of the selected pump model.

\begin{tabular}{lccc}
\hline Pressure side diameter, $D_{1}$ & $50 \mathrm{~mm}$ & Flow rate, qd & $12.5 \mathrm{~m} 3 / \mathrm{h}$ \\
\hline Impeller out diameter, $D_{2}$ & $160 \mathrm{~mm}$ & Head, hd & $32 \mathrm{~m}$ \\
Impeller out width, $b_{2}$ & $6 \mathrm{~mm}$ & Efficiency, $\eta$ & $56 \%$ \\
Long blades & & 4 & 4 \\
Splitter & 4 & 4 \\
Splitter inlet diameter & $\mathrm{di} / \mathrm{mm}$ & $104 \mathrm{~mm}$ & \\
Power P & $3 \mathrm{~kW}$ & Speed, $n$ & $2900 \mathrm{rpm}$ \\
\hline
\end{tabular}
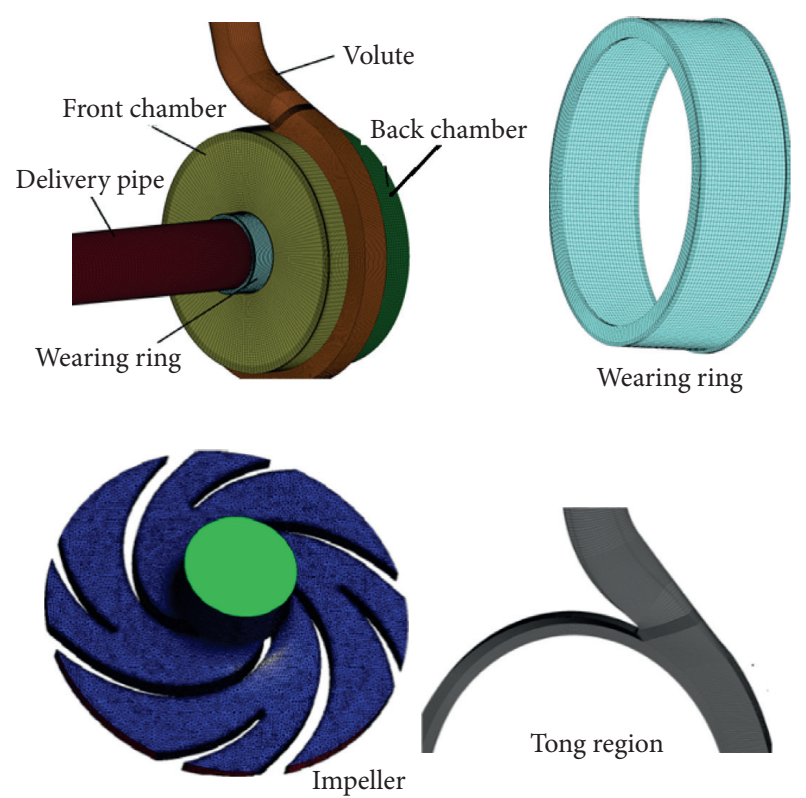

FIgURE 3: The whole created mesh areas of the selected centrifugal pump model.
All boundary conditions were set. The steady calculations were first performed to make an initial flow field available for the unsteady simulation. In each time step, $1 \times 12^{-5}$ was set. The simulation was conducted for 12 complete impeller rotations to achieve a steady simulation outcome. Flow field, pressure, and absolute velocity data were further studied in the study. There was one interface between the two domains when simulating a PAT model. This interface was found between the stationary volute and the rotating impeller domain. The interface between domains is created using the "interface" icon on the toolbar. The entire interface was designed, and the interface type was set to a fluid-fluid interface. The general grid interface (GGI) connection option was selected as the interface model for the two separate individual rotary and stator fields. The stationary blade was used for frame change.

\section{Results and Discussion}

4.1. Hydraulic PAT Performs Characteristics Curves. The speed of a turbine is determined by the amount of load used. At constant flow rate and head, the turbine speed decreases when the turbine uses a higher load more than the design load; with the decrease of the burden placed on a turbine, whereas the head and flow rate remain constant, the turbine speed increases [29]. The same principle applies when hydraulic pumps are used as a turbine at a specified site with a continuous flow rate and contribute significantly to determining the turbine's performance characteristics. As the PAT load is further reduced, the PAT's speed reaches a maximum value at which the PAT can deliver no torque. This speed is called runaway speed. The PAT's runaway speed was obtained to be approximately $2250 \mathrm{rpm}$, as can be seen in Figure 4, while Figure 5 shows the relationship between speed and power. From the results, as the speed of PAT increases, the power output also rises until it reaches $1750 \mathrm{rpm}(512 \mathrm{kw})$, after which the power began to drop progressively. Increase in PAT's efficiency with the increase in impeller's rotational speed, until it reaches $1500 \mathrm{rpm}$ should be also mentioned, as shown in Figure 6. It means that when PAT operates beyond $1500 \mathrm{rpm}$, the efficiency of the PAT will decrease. PAT efficiency behaves equally as the power output of the PAT. Therefore, it can be concluded that the best-operating conditions for selected PAT could be achieved when it operates between 1000 and $1750 \mathrm{pm}$. 


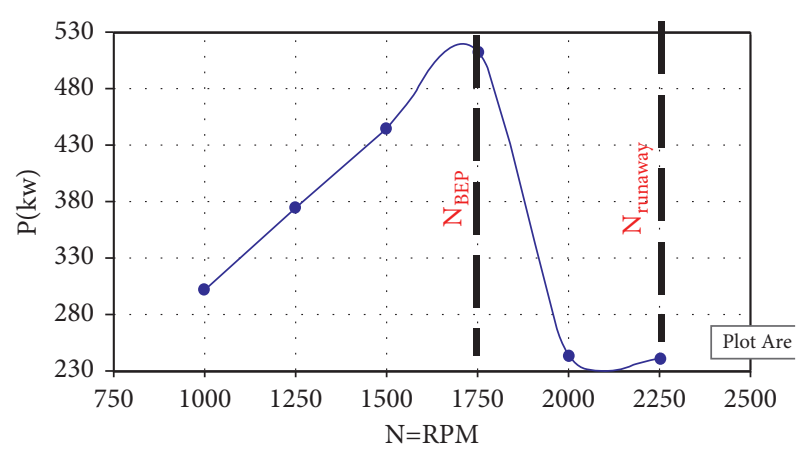

Figure 4: Power vs. rotational speed for selected PAT at $Q_{t}=1.2 \mathrm{~m}^{3} / \mathrm{s}$.

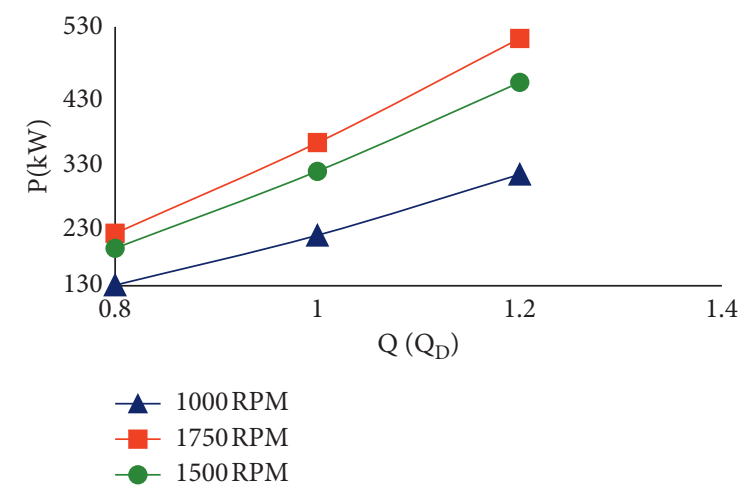

FIgure 5: Power vs. rotational speed for selected PAT.

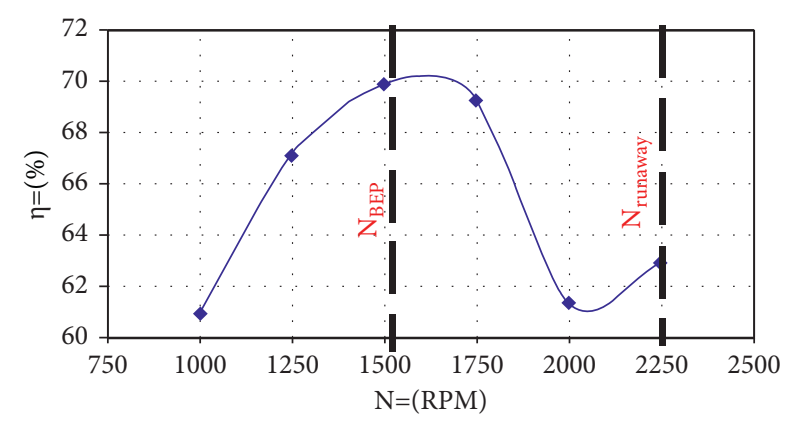

Figure 6: Power vs. efficiency for selected PAT at $Q t=1.2 \mathrm{~m}^{3} / \mathrm{s}$.

4.2. Performance of PAT Predicted Based on Pump Performance. PAT simulation results acquired from ANSYS CFX was used to evaluate the performance parameters of the PAT. It is essential to recognise these parameters for PAT performance under different flow rate conditions. They consist of the head, power, and nondimensionless coefficients such as head, flow, and power coefficient. Pump mode data can predict PAT performance by using the pump BEP. This section will determine the PAT performance using the BEP of the pump and compare anticipated results with the CFD simulation result. The performance parameters of PAT could be predicted by considering pump mode performance. The public affinity laws are used to establish relationships between the performance parameters of similar machines operating under similar kinematic conditions. It is essential to know the following dimensionless parameters, which are vital in determining the turbine's performance characteristics. They consist of a head, flow, and power coefficient. The similarities between these parameters are that the variables with the particular coefficient are made dimensionless through normalising with a diameter $(D)$ and rotation speed $(N)$. Except for the flow coefficient, previous and latter parameters call for one additional variable to normalise. The dimensionless coefficients result realised from the PAT numerical simulation has also been plotted as displayed in Figure 5, showing the head coefficient, flow coefficient, and power coefficient. These results show the differences which exist among these coefficients. Thus, Figure 6 indicates the difference in the head coefficient at different flow coefficient levels and different rotational speeds. It can be witnessed from the results that the increase in the head coefficient increases the flow coefficient, but this occurs at a different rotational speed; thus, increase in rotational speed decreases the head coefficient as shown in Figure 7. Figure 8 shows the difference in the flow coefficient via the power coefficient. One can observe from the figure that the power coefficient performs comparably with the PAT flow coefficient under different flow rate conditions. It is characterised by reducing the value as the flow coefficient drops. Figure 9 shows the head coefficient vs. flow coefficient curves of a selected PAT at a different flow rates.

The nondimensional parameters at various rotational speeds have been studied (let us say $\phi=0.8$ ), as tabulated in Table 3. The study discovered that an increase in speed increases power coefficient $(\pi)$ and efficiency $\eta$. Nevertheless, their differences in $\psi$ were not much except at higher speeds. The results are as shown in the curves below, with the BEP points at different rotational speeds also indicated. The power output and efficiency were found better in the speed range of $1000-1200 \mathrm{rpm}$. As PAT operates in the opposite direction of pump mode operation, the energy converted from hydraulic to mechanical might not be effectual at higher speeds, causing its better performance at the lower speed level.

4.3. Transient Static Pressure Supply under Diverse Flow Rate in Lieu of Centrifugal Pump Impeller. Pressure distribution under different flow conditions and rotational speed in pump as turbine fluid domain are displayed in Figure 10. From the results, pressure progressively intensified in a streamwise way with the pressure side recording the maximum. Flow parting could be observed at the impeller blade leading edge. The flow at the inlet is not at a tangent with a blade with uniformed flow observed near the blade, which causes flow parting to occur on the blade surface. Minimal pressure was found at the impeller inlet along the suction area, representing location cavitation which usually occurs in pumps.

It is observed from Figure 11 that static pressure was asymmetrically disseminated. The minimum pressure happens at the blade suction area. Pressure increases as the flow rate reaches the lowest values, while it decreases with increasing flow rates, as shown in Figure 11(b). Comparing the 


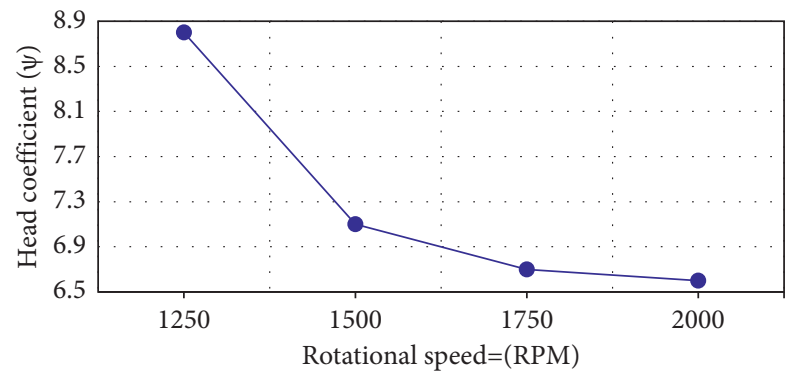

FIGURE 7: Rotational speed vs. head coefficient characteristics curve of selected PAT at $Q t=0.8 \mathrm{~m}^{3} / \mathrm{s}$.

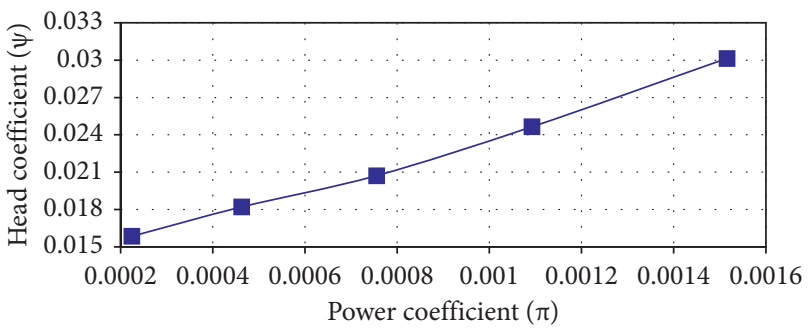

Figure 8: Power coefficient vs. flow coefficient curve of selected $\mathrm{PAT}$ at $\mathrm{Q} t=0.8 \mathrm{~m}^{3} / \mathrm{s}$ and $n=1500 \mathrm{rpm}$.

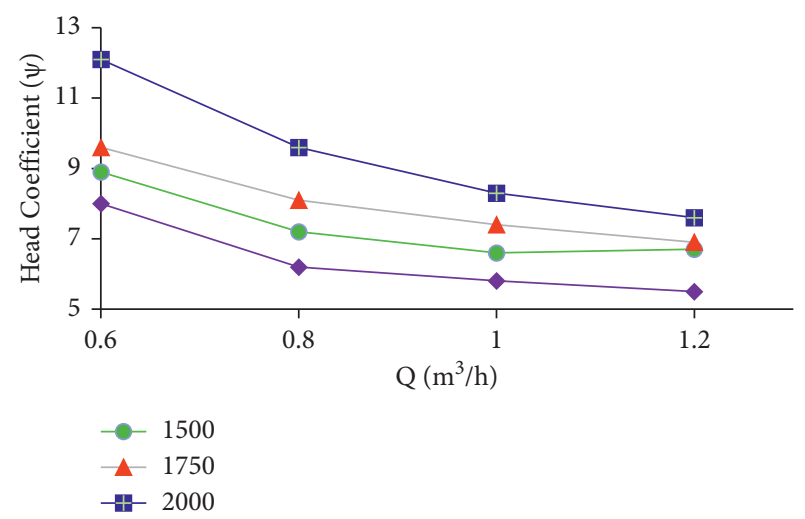

FIGURE 9: Head coefficient vs. flow coefficient curves of a selected $\mathrm{PAT}$ at a different flow rates.

TABle 3: Parameters at $\phi=0.8$ at different rotational speeds for the original impeller.

\begin{tabular}{lcccc}
\hline$N(\mathrm{rpm})$ & $\psi$ & $\pi$ & $\phi$ & $\eta(\%)$ \\
\hline 1250 & 8.8 & 0.16 & 7.71 & 0.00202 \\
1500 & 7.1 & 0.07 & 6.45 & 0.00207 \\
1750 & 6.6 & 0.08 & 5.53 & 0.00184 \\
2000 & 6.4 & 0.04 & 4.84 & 0.00106 \\
\hline
\end{tabular}

two selected rotational speeds under three flow conditions from $Q=0.08 \mathrm{~m}^{3} / \mathrm{s}$ to $Q=1.2 \mathrm{~m}^{3} / \mathrm{s}$, a rise in the flow rate also brought about an increase in drop closer to the exit duct of the volute. Proper recirculation of flow could be observed at the impeller suction area due to lower flow rates, though the flow on the pressure side is smooth. On the contrary, as the flow rate increases, flow parting along the pressure side occurs, bringing about continuous flow movement in the pressure side. This movement in the suction side of the impeller blade drops as the flow rate rises.

4.4. Transient Velocity Distribution in the PAT Model for a Selected Centrifugal Pump. Hydrodynamics of flow in PAT was numerically calculated using CFD to find the supply of actual parameters defining hydrodynamics flow in the pump, which interconnects the PAT characteristics' geometric model. Figure 12 shows the velocity in the PAT colored by relative velocity distribution. Considering the volute shape, one could observe the velocity increase with a rise flow rate. Flow then moves smoothly in the volute region at a minimal flow rate. Moreover, it slows down after striking the trailing edge of the impeller, after which relative fluid velocity begins to once again increase to some extent. The CFD model shows a trend of velocity differences with changes in rotational speed. It was also observed that, as water enters the suction side, relative velocity intensified next to the curving of the blade in the streamwise direction as the passage bit by bit gets smaller. In summary, a portion of the simulation was performed by the PAT impeller as a feedback turbine as a result of reaction from the pressure drop, with a change in kinetic energy also playing a role.

4.5. Transient Static Pressure Distribution for Centrifugal Pump Impeller. In analysing flow features of the centrifugal pump in pump mode, pressure and velocity contour plots and vectors are employed. The streamlines of the $3 \mathrm{D}$ models are plotted to examine the flow design in a centrifugal pump. Figure 13 displays the static pressure transfer of the designated PAT model under a diverse flow rate at $n=1750 \mathrm{rpm}$. The results show that lower static pressure was observed at the blade leading edge. As kinetic energy flowed and transported to fluid, the static pressure progressively increases. The figure shows that maximum pressure was monitored on the blade side, whereas minimal pressure was also detected on the blade suction side at the same radial position. As the fluid leads, it is a way to the volute casing. The static pressure further increased, as shown in Figure 13, which could be attributed to the conversion of the fluid's kinetic energy to pressure energy because of the increasing casing cross-segment region. Figure 14 also displays the velocity delivery of the designated PAT model under diverse flow rate, $n=1750 \mathrm{rpm}$. 

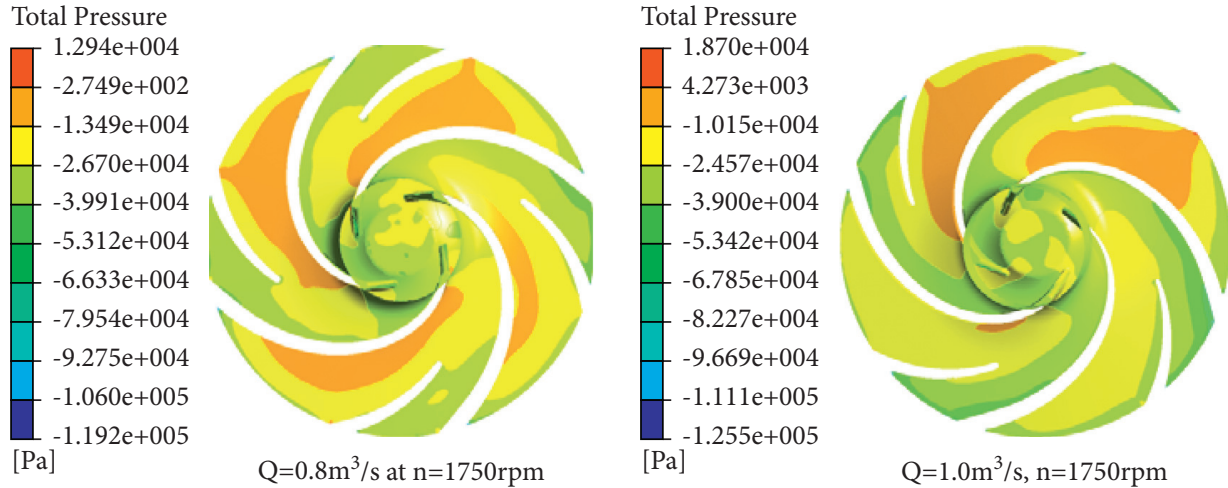

$\mathrm{Q}=1.0 \mathrm{~m}^{3} / \mathrm{s}, \mathrm{n}=1750 \mathrm{rpm}$

FIgURE 10: Total pressure distribution on the PAT impeller at a different flow rate.

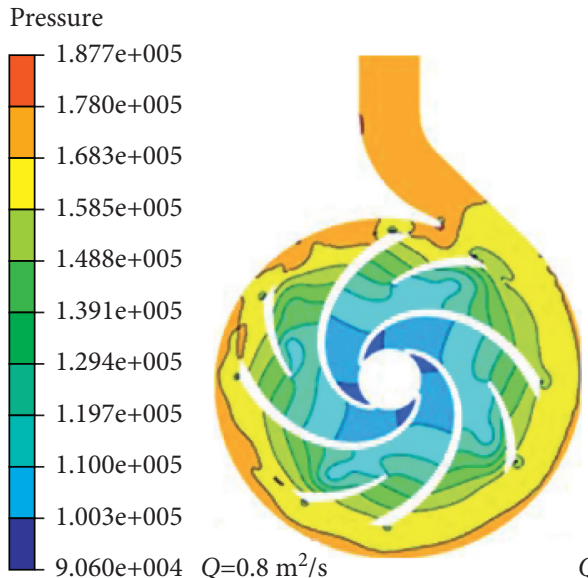

$[\mathrm{Pa}]$

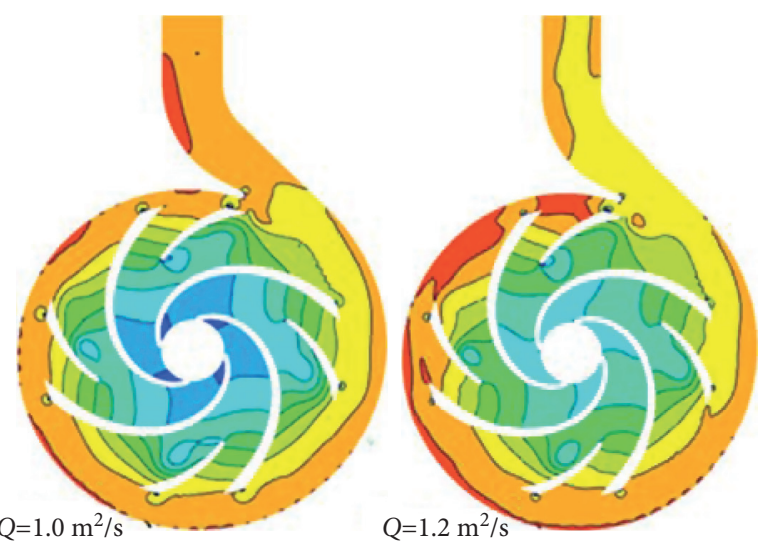

(a)

\section{Pressure}
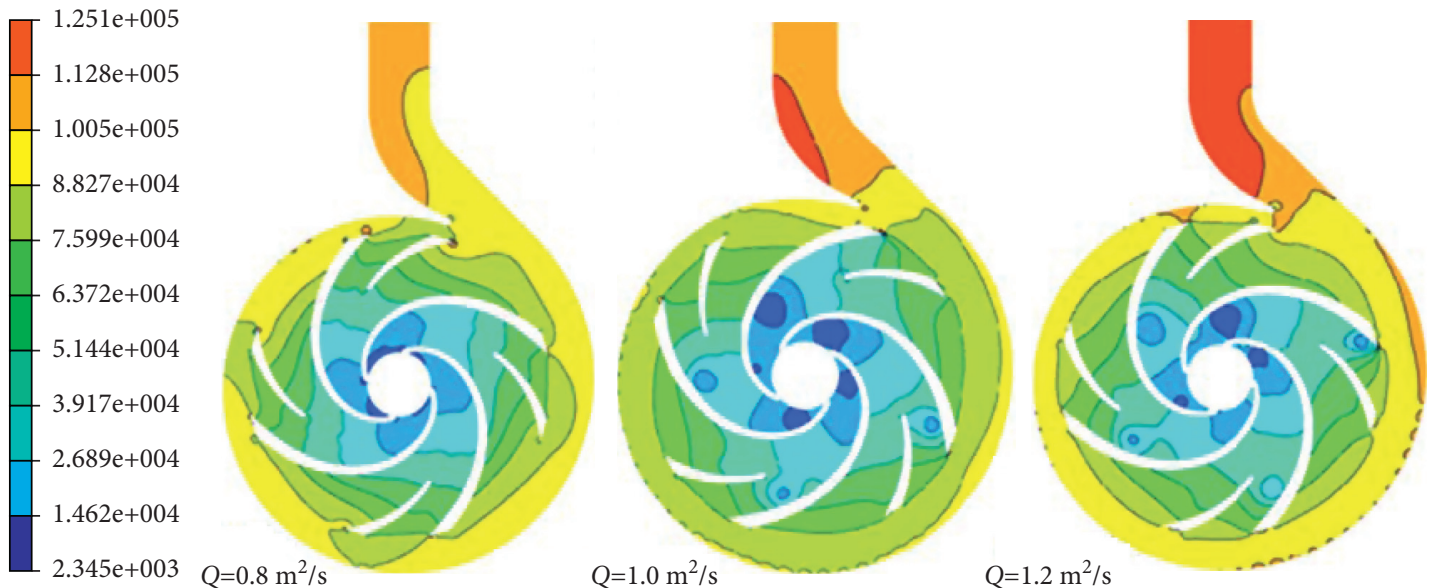

$[\mathrm{Pa}]$

(b)

Figure 11: (a) 3D pressure dissemination for the PAT model under the dissimilar flow rate, $n=1750 \mathrm{rpm}$. (b) 3D pressure dissemination for the PAT model under different flow rates, $n=1500 \mathrm{rpm}$. 


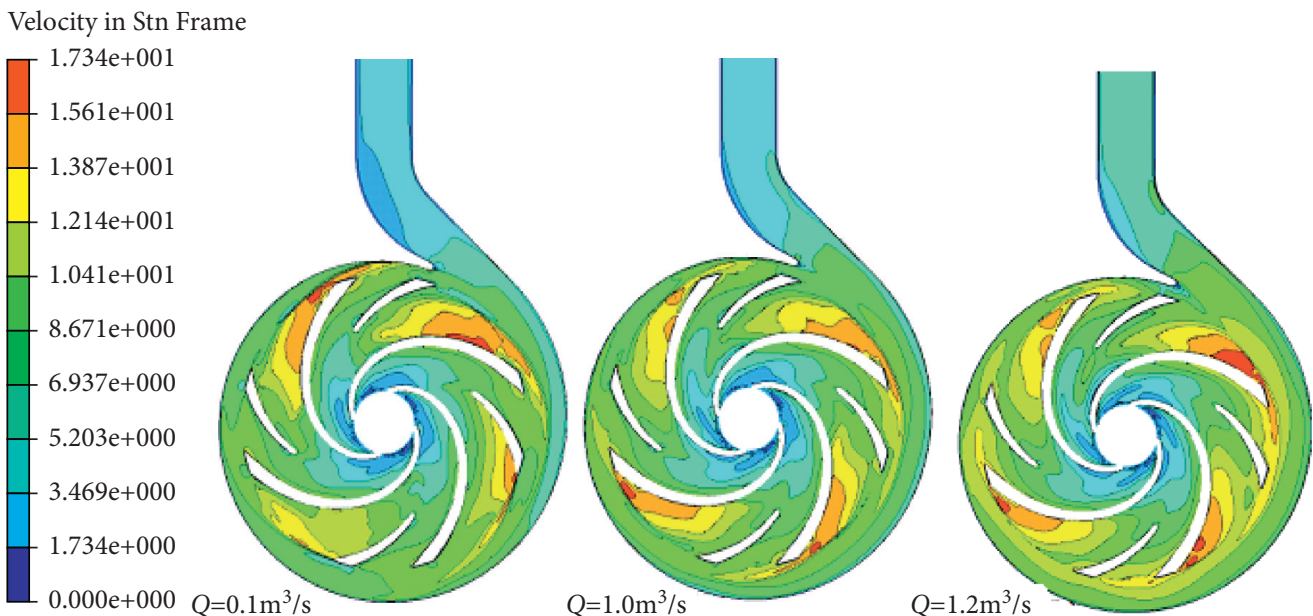
$\left[\mathrm{m} \mathrm{s}^{\wedge}-1\right]$

FIgURE 12: Absolute velocity delivery of the designated PAT model under diverse flow rate, $n=1750 \mathrm{rpm}$.

\section{Pressure}

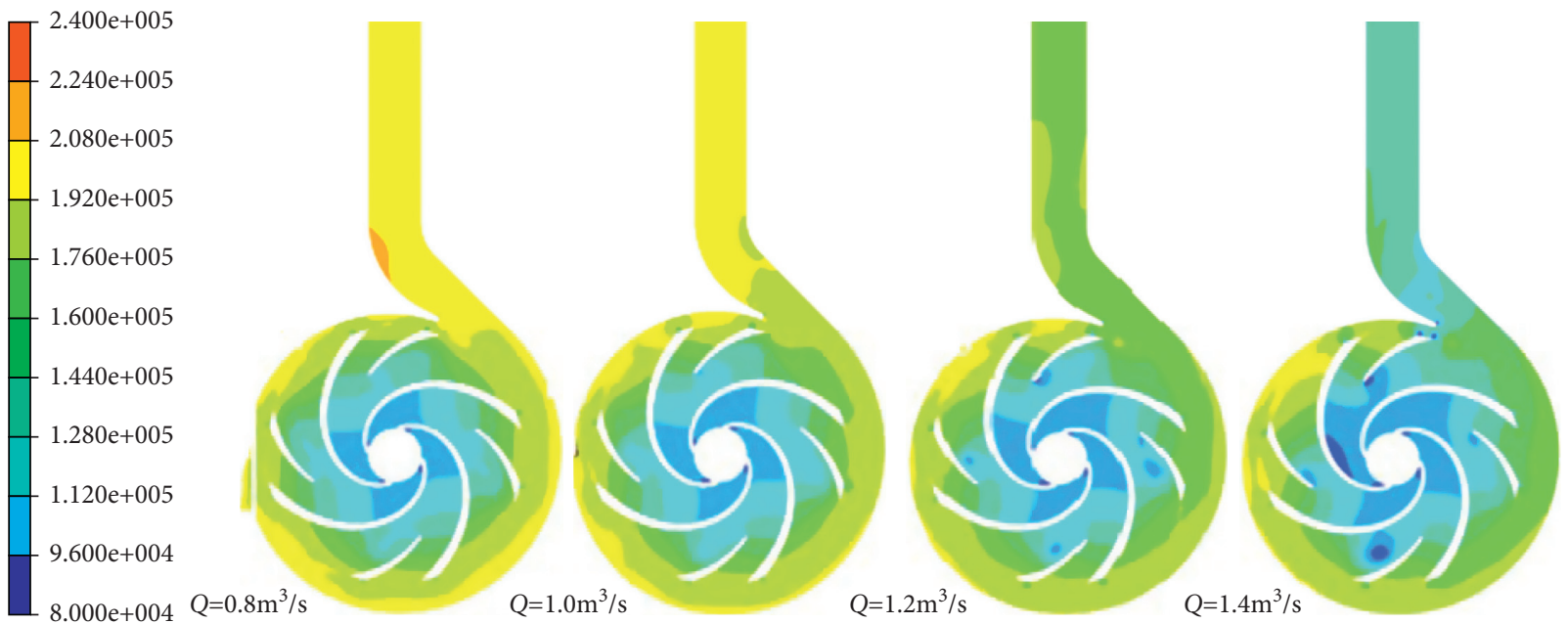

$[\mathrm{Pa}]$

Figure 13: Static pressure delivery of the designated PAT model under diverse flow rate, $n=1750 \mathrm{rpm}$.

Velocity
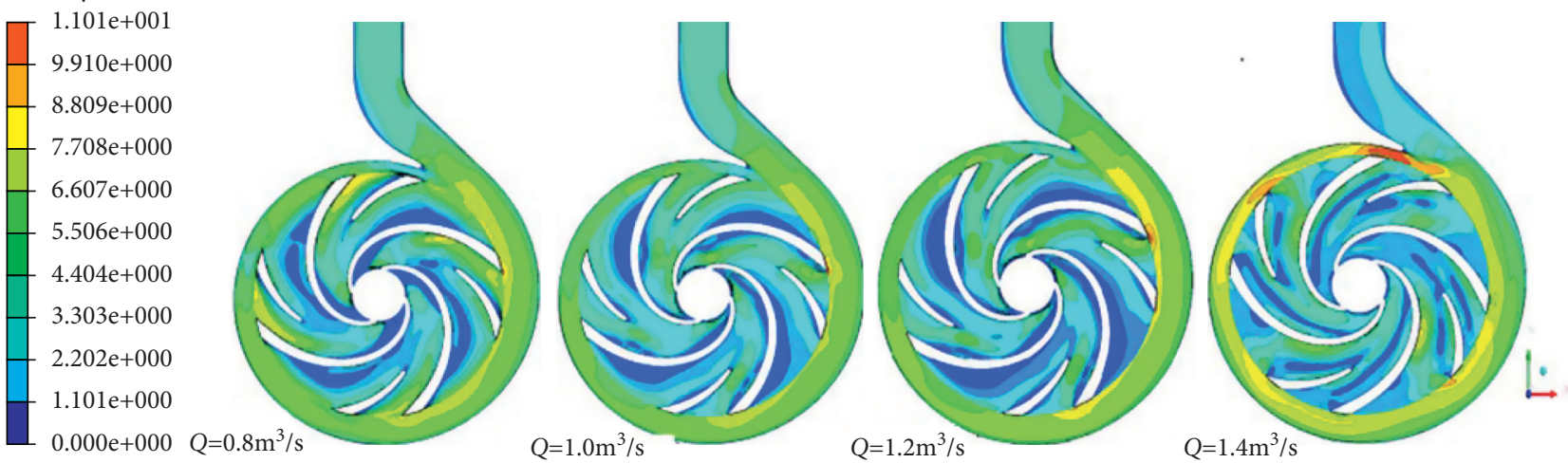

$\left[\mathrm{m} \mathrm{s}^{\wedge}-1\right]$

FIGURE 14: Velocity distribution for the selected centrifugal pump model at different flow rates, $N=1750 \mathrm{rpm}$. 


\section{Conclusion}

In this study, the comparison of numerical studies results obtained under different flow and speed conditions was investigated. From the study, the following conclusions were made:

(A) The speed of a turbine is determined by the amount of load used. At constant flow rate and head, the turbine speed decreases when the turbine uses a higher load more than the design load; with the decrease of the burden placed on a turbine, whereas the head and flow rate remain constant, the turbine speed increases. The same principle applies when hydraulic pumps are used as a turbine at a specified site with a continuous flow rate and contribute significantly to determining the turbine's performance characteristics. As the PAT load is further reduced, the PAT's speed reaches a maximum value that the PAT can deliver no torque. This speed is called runaway speed. The runaway speed of the PAT was obtained to be approximately $2250 \mathrm{rpm}$.

(B) Increase in PAT's efficiency with the increased rotational speed of the impeller till it reaches $1500 \mathrm{rpm}$ should also be mentioned. It means that when PAT operates beyond $1500 \mathrm{rpm}$, the efficiency of the PAT will decrease. In comparison with Figures 6 and 7, PAT efficiency behaves equally as the power output of the PAT. Therefore, it can be concluded that the best-operating conditions for selected PAT could be achieved when it operates between $1000 \mathrm{rpm}$ and $1750 \mathrm{rpm}$.

(C) Pressure distribution under different flow conditions and rotational speed in the pump as turbine fluid domain. From the results, pressure progressively intensified in a streamwise way with the pressure side recording the maximum. Flow parting could be observed at the impeller blade leading edge. The flow at the inlet is not at a tangent with the blade with ununiformed flow observed near the blade, which causes flow parting to occur on the blade surface. Minimal pressure was found at the impeller inlet along the suction area, representing location cavitation typically occurs in pumps.

In summary, PAT simulation results acquired from ANSYS CFX have been used to evaluate the PAT's performance parameters. It is essential to recognise these parameters for PAT performance under different flow rate conditions. They consist of the head, power, and nondimensionless coefficients such as head, flow, and power coefficient. Pump mode data can predict PAT performance by using the pump BEP.

\section{Data Availability}

The data are openly available in a public repository that issues datasets with DOIs. The authors confirm that the data supporting the findings of this study are available within the article and could be obtained upon request. The data, generated at a central, large-scale facility, are available upon request. Raw data were generated at Jiangsu University Lab. The derived data supporting the findings of this study are available from the corresponding author upon request.

\section{Conflicts of Interest}

The authors declare that they have no conflicts of interest.

\section{Acknowledgments}

This study was supported by the National Science Foundation of China, under Grant nos. 71974081, 71704066, and 71971100 , and special funds of the National Social Science Fund of China (Grant no. 18VSJ038).

\section{References}

[1] J. González and C. Santolaria, "Unsteady flow structure and global variables in a centrifugal pump," Journal of Fluids Engineering, vol. 128, no. 5, pp. 937-946, 2006.

[2] B. K. Gandhi, S. N. Singh, and V. Seshadri, "Performance characteristics of centrifugal slurry pumps," Journal of Fluids Engineering, vol. 123, no. 2, pp. 271-280, 2001.

[3] H. Nautiyal, A. Varun, and A. Kumar, "Reverse running pumps analytical, experimental and computational study: a review," Renewable and Sustainable Energy Reviews, vol. 14, no. 7, pp. 2059-2067, 2010.

[4] S. V. Jain and R. N. Patel, "Investigations on pump running in turbine mode: a review of the state-of-the-art," Renewable and Sustainable Energy Reviews, vol. 30, pp. 841-868, 2014.

[5] H. Nautiyal, V. Varun, A. Kumar, and S. Y. S. Yadav, "Experimental investigation of centrifugal pump working as turbine for small hydropower systems," Energy Science and Technology, vol. 1, pp. 79-86, 2011.

[6] A. J. Stepanoff, Centrifugal and Axial Flow Pumps, Design and Applications, John Wiley \& Sons, New York, NY, USA, 1957.

[7] S. Childs, "Convert pumps to turbines and recovers HP," Hydrocarbon Processing and Petroleum Refiner, vol. 41, pp. 173-174, 1962.

[8] R. K. Sharma, Small Hydroelectric Projects-Use of Centrifugal Pumps as Turbines, Kirloskar Electric Co, Bangalore, India, 1984.

[9] S. Gopalakrishnan, "Power recovery turbines for the process industry," in Proceedings of the Third International Pump Symposium, pp. 3-11, Texas A\&M University, Houston, TX, USA, September 1986.

[10] H. Diederich, "Verwendung von kreiselpumpen als turbinen," KSB Techn Ber, vol. 12, pp. 30-36, 1967.

[11] K. Grover, Conversion of Pumps to Turbines, GSA Inter corporate, Katonah, NY, USA, 1982.

[12] A. Morabito and P. Hendrick, "Pump as turbine applied to micro energy storage and smart water grids: a case study," Applied Energy, vol. 241, pp. 567-579, 2019.

[13] M. Rossi, A. Nigro, and M. Renzi, "Experimental and numerical assessment of a methodology for performance prediction of pumps-as-turbines (PaTs) operating in off-design conditions," Applied Energy, vol. 248, pp. 555-566, 2019.

[14] B. Luo and X. C. L. Wang, "Numerical simulation of flowinduced vibration of double-suction centrifugal pump as turbine," Journal Drainage Irrigation Mechanical Engineering, vol. 37, pp. 313-318, 2019. 
[15] I. M. Hossain, S. Ferdous, and T. Jamal, "Pump-as-turbine (PAT) for small-scale power generation: a comparative analysis," in Proceedings of the 2014 3rd International Conference on the IEEE Developments in Renewable Energy Technology (ICDRET), pp. 1-5, Dhaka, Bangladesh, May 2014.

[16] J.-M. Chapallaz, P. Eichenberger, and G. Fischer, "Manual on pumps used as turbines," Vieweg, vol. 11, 1992.

[17] S. Derakhshan and A. Nourbakhsh, "Theoretical, numerical and experimental investigation of centrifugal pumps in reverse operation," Experimental Thermal and Fluid Science, vol. 32, no. 8, pp. 1620-1627, 2008.

[18] P. Vasanthakumar, J. Krishnaraj, S. Karthikayan, T. Vinoth, and S. K. Arun Sankar, "Investigation on reverse characteristics of centrifugal pump in turbine mode: a comparative study by an experimentation and simulation," Materials Today: Proceedings, vol. 4, no. 2, pp. 693-700, 2017.

[19] M. Gantar, "Propeller pumps running as turbines," in Proceedings of the Conference on Hydraulic Machinery, pp. 237248, Ljubljana, Slovenia, August 1988.

[20] H. H. Anderson, "Borehole pumps," Centrifugal Pumps and Allied Machinery, vol. 4, pp. 177-185, 1993.

[21] D. Adu, J. Zhang, M. Jieyun, S. N. Asomani, and M. Osman Koranteng, "Numerical investigation of transient vortices and turbulent flow behaviour in centrifugal pump operating in reverse mode as turbine," Materials Science for Energy Technologies, vol. 2, no. 2, pp. 356-364, 2019.

[22] H. Wang, Y. Wang, C. Fan et al., "Material consumption and carbon emissions associated with the infrastructure construction of 34 cities in northeast China," Complexity, vol. 2020, Article ID 4364912, 20 pages, 2020.

[23] Z. Cao, M. Liu, and P. Wu, "Experiment investigation and numerical simulation of Snowdrift on a typical large-span retractable roof," Complexity, vol. 2019, Article ID 5984804, 14 pages, 2019.

[24] K. Ren, H. Li, S. Li, and H. Dong, "Voltage stability analysis of front-end speed controlled wind turbine integrated into regional power grid based on bifurcation theory," Complexity, vol. 2020, Article ID 8816334, 11 pages, 2020.

[25] D. Flórez-Orrego, I. B. Henriques, T.-V. Nguyen et al., "The contributions of prof. Jan Szargut to the exergy and environmental assessment of complex energy systems," Energy, vol. 161, pp. 482-492, 2018.

[26] Y. Zhang, Y. Xu, Y. Zheng et al., "Multiobjective optimization design and experimental investigation on the axial-flow pump with orthogonal test approach," Complexity, vol. 2019, Article ID 1467565, 14 pages, 2019.

[27] X. Xu, X. Yuan, M. Cui, Y. Yuan, and L. Qi, "Joint optimization of energy conservation and migration cost for complex systems in edge computing," Complexity, vol. 2019, Article ID 6180135, 14 pages, 2019.

[28] Y. L. Zhang, S. Q. Yuan, Z. Jinfeng et al., "Numerical investigation of the effects of splitter blades on the cavitation performance of a centrifugal pump," IOP Conference Series: Earth and Environmental Science, vol. 22, Article ID 052003, 2014.

[29] Z. Jinfeng, A. Daniel, S. Lv, and K. Majid, "Small hydropower by using pump as turbine for power generation in Southern Africa," Current Science, vol. 118, no. 3, 2019. 